Article

\title{
Biofilm Inhibitory Abscisic Acid Derivatives from the Plant-Associated Dothideomycete Fungus, Roussoella sp.
}

\author{
Chayanard Phukhamsakda ${ }^{1,+} \mathbb{1}^{\mathbb{D}}$, Allan Patrick G. Macabeo ${ }^{2,3,+}$, Kamila Tomoko Yuyama $^{2}$, \\ Kevin David Hyde ${ }^{1}$ and Marc Stadler ${ }^{2, *}$ (iD \\ 1 Center of Excellence in Fungal Research, Mae Fah Luang University, Chiang Rai 57100, Thailand; \\ chayanard91@gmail.com (C.P.); kdhyde3@gmail.com (K.D.H.) \\ 2 Department of Microbial Drugs, Helmholtz Centre for Infection Research and German Centre for Infection \\ Research (DZIF), partner site Hannover/Braunschweig, Inhoffenstrasse 7, 38124 Braunschweig, Germany; \\ agmacabeo@ust.edu.ph (A.P.G.M.); kamilatomoko@gmail.com (K.T.Y.) \\ 3 Laboratory for Organic Reactivity, Discovery and Synthesis (LORDS), Research Center for the Natural and \\ Applied Sciences, University of Santo Tomas, 1015 Manila, Philippines \\ * Correspondence: Marc.Stadler@helmholtz-hzi.de; Tel.: +49-531-6181-4240 \\ + These authors contributed equally to this work.
}

Received: 13 August 2018; Accepted: 29 August 2018; Published: 30 August 2018

\begin{abstract}
Roussoella species are well recorded from both monocotyledons and dicotyledons. As part of a research program to discover biologically active compounds from plant-associated Dothideomycetes in Thailand, the strain Roussoella sp. (MFLUCC 17-2059), which represents an undescribed species, was isolated from Clematis subumbellata Kurz, fermented in yeast-malt medium and explored for its secondary metabolite production. Bioassay-guided fractionation of the crude extract yielded the new abscisic acid derivative, roussoellenic acid (1), along with pestabacillin B (2), a related congener, and the cyclodipeptide, cyclo(S-Pro-S-Ile) (3). The structure of $\mathbf{1}$ was determined by 2D NMR spectroscopy and HR-ESIMS data analysis. Compounds $\mathbf{1}$ and $\mathbf{2}$ showed inhibitory activity on biofilm formation by Staphylococcus aureus. The biofilm formation of S. aureus was reduced to $34 \%$ at $16 \mu \mathrm{g} / \mathrm{mL}$ by roussoellenic acid (1), while pestabacillin B (2) only showed 36\% inhibition at $256 \mu \mathrm{g} / \mathrm{mL}$. In addition, compound 1 also had weak cytotoxic effects on L929 murine fibroblasts and human KB3-1 cancer cells.
\end{abstract}

Keywords: Anti-biofilm; Ascomycota; Pleosporales; structure elucidation

\section{Introduction}

With over sixty thousand estimated species, the phylum Ascomycota is known to be the most diverse group in the fungal kingdom [1-3]. While many studies have reported the richness of biologically active secondary metabolites in this group of fungi, little is known on natural products produced by plant-associated Ascomycota, especially the endophytes and saprobes present in vascular plants [4-6].

Roussoellaceae Liu et al. can be distinguished from other families of Pleosporales (class Dothideomycetes, Ascomycota) by its morphology and is well-resolved in phylogenetic analyses [7]. At present, there is a limited knowledge on the secondary metabolite production of these genera and thus studies are warranted to probe chemical constituents with promising biological activity. The first chemical study on Roussoella hysterioides has recently led to the discovery of two novel tetracyclic fusicoccanes, which are oxidized diterpenoid congeners with unique bent structural frameworks [8]. One of these compounds, roussoellol B showed inhibition against the phytopathogenic fungus, Cochliobolus miyabeanus. Follow up investigations on two additional species, R. japanensis KT1651 and Roussoella sp. DLM33, yielded two highly oxidized xanthone derivatives [9] and a dichlorinated 
polyketide, respectively [10]. During our exploration of new Dothideomycetes in Thailand, a Roussoella sp. (MFLUCC 17-2059) was isolated and identified from the decaying parts of Clematis subumbellata Kurz (Ranunculaceae). As part of a research program to identify biologically active constituents from Dothideomycetes, we herewith report the isolation, structure elucidation and biological activity of a new abscisic acid derivative (1) along with two known fungal metabolites (2-3) (Figure 1).
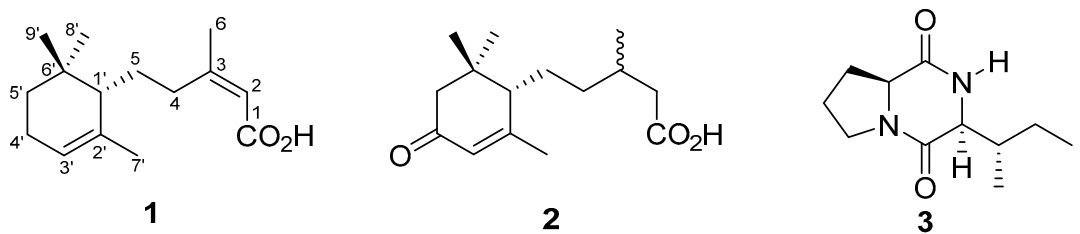

Figure 1. Abscisic acid derivatives and cyclodipeptide from Roussoella sp. MFLUCC 17-2059.

\section{Results and Conclusions}

Roussoella sp. was isolated from a dried branch of Clematis subumbellata Kurz collected in Chiang Rai, Thailand in 2017. The fungus formed cream to yellowish colonies on MEA. The morphological characters of strain MFLUCC 17-2059 resemble those of Roussoella mangrovei. However, the results of a multigene phylogenetic analysis suggested that the fungus represents a distinct species. A formal taxonomic description of Roussoella sp. will be published elsewhere.

Submerged fermentation of Roussoella sp. MFLUCC 17-2059 in shake flask batches on yeast-malt medium ( $\mathrm{pH}$ 6.3) resulted in a luxuriant growth, and entirely consuming glucose after seven days at $25^{\circ} \mathrm{C}$. The pooled broth extracts were extracted with ethyl acetate to recover the organic metabolites. The crude extracts from submerged cultures showed antimicrobial activities against Bacillus subtilis, therefore the extracts were subjected to a bioactivity-guided fractionation using reversed-phase HPLC. B. subtilis was selected as the indicator organism, leading to the isolation of the new metabolite roussoellenic acid (1). The crude extract was fractionated on reversed-phase HPLC yielding eighteen fractions. Three of those (No. 6, 17, and 18) contained small molecules (LC-MS) and were further purified by RP-HPLC to yield three compounds in quantities sufficient for full spectroscopic characterization.

Roussoellenic acid (1) was isolated as a colorless syrup after repeated reversed-phase HPLC purification of fraction seventeen. Its UV spectrum was characteristic of an $\alpha, \beta$-unsaturated carboxylic acid with absorption maxima at $218 \mathrm{~nm}(\log \varepsilon=4.1)$. The molecular formula of 1 was deduced from its protonated molecular ion peak at $m / z 237.1853[\mathrm{M}+\mathrm{H}]^{+}$by high-resolution mass spectrometry (HRMS; $\Delta \mathrm{mmu}+0.4)$ as $\mathrm{C}_{15} \mathrm{H}_{24} \mathrm{O}_{2}$ and further substantiated by ${ }^{13} \mathrm{C}-\mathrm{NMR}$ spectroscopic data. Further ESI-MS/MS fragmentation of this ion signal resulted in two abundant diagnostic ions: $m / z 191$ suggested loss of formic acid $(\Delta m / z 46)$, and $m / z 151$ attributed to the $\alpha$-fragmentation with cleavage of the olefinic side chain of the abscisic acid backbone. The formula indicated four indices of hydrogen deficiency.

The ${ }^{1} \mathrm{H}-\mathrm{NMR}$ spectrum of $\mathbf{1}$ in $\mathrm{MeOH}-d_{4}$ featured singlet signals corroborated to four methyl groups [ $\delta_{\mathrm{H}} 0.89\left(3 \mathrm{H}, \mathrm{s} ; \mathrm{CH}_{3}-9^{\prime}\right), 1.00\left(3 \mathrm{H}, \mathrm{s} ; \mathrm{CH}_{3}-8^{\prime}\right), 1.72\left(3 \mathrm{H}, \mathrm{d}, 1.5 \mathrm{~Hz} ; \mathrm{CH}_{3}-7^{\prime}\right), 1.90\left(3 \mathrm{H}, \mathrm{s} ; \mathrm{CH}_{3}-6\right]$, eight methylene protons $\left[\delta_{\mathrm{H}} 1.14\left(1 \mathrm{H}, \mathrm{dd} J=7.1,6.0 \mathrm{~Hz} ; \mathrm{H}-5^{\prime} \mathrm{b}\right), 2 \times 1.48\left(2 \times 1 \mathrm{H}, \mathrm{m} ; \mathrm{H}-5 \mathrm{~b}\right.\right.$ and $\left.\mathrm{H}-5^{\prime} \mathrm{a}\right)$, 1.61 (1H, m; H-5a), 1.97 (2H, m; H-4'), 2.48 (1H, ddd, 4.9, 10.5, 11.5 Hz; H-4b) and 2.82 (1H, ddd, 4.9, $10.5,11.5 \mathrm{~Hz} \mathrm{~Hz} ; \mathrm{H}-4 \mathrm{a})]$, an aliphatic methine proton $\left[\delta_{\mathrm{H}} 1.50, \mathrm{~m} ; \mathrm{H}-1^{\prime}\right]$ and two signals of alkenyl protons $\left[\delta_{\mathrm{H}} 5.31\left(1 \mathrm{H}\right.\right.$, brs; $\left.\mathrm{H}-3^{\prime}\right)$ and $5.62(1 \mathrm{H}, \mathrm{s} ; \mathrm{H}-2)$. The ${ }^{13} \mathrm{C}-\mathrm{NMR}$ spectrum revealed fifteen carbon resonances, consisting of four methyl, four methylene, one $\mathrm{sp}^{3}$ methine, two olefinic methine, one $\mathrm{sp}^{3}$ quaternary, two olefinic quaternary, and one carboxyl group.

The constitution of structure $\mathbf{1}$ was unambiguously established through homonuclear and heteronuclear correlation experiments such as proton-proton Correlation Spectroscopy (COSY) and Heteronuclear Multiple Bond Correlation (HMBC). All long-range correlations are summarized in Table 1, and structurally relevant correlations of the COSY and HMBC spectra are presented in Figure 2. These structural characteristics resembled a dihydro- $\alpha$-ionylidene skeleton. In the COSY spectrum, 
three distinct spin sets of C-2-C-6 (allylic), C-4-C-5-C- $1^{\prime}$ and C-7' (allylic) $-C-2^{\prime}-C-3^{\prime}-C-4^{\prime}-C-5^{\prime}$ were observed. A complete assignment of all protons and carbons and the establishment of their connectivities were obtained using the HMBC (Figure 2) and Heteronuclear Single Quantum Coherence (HSQC)data. Downfield shifts of $\mathrm{H}-4 \mathrm{~b}\left(\delta_{\mathrm{H}} 2.48\right)$ and $\mathrm{H}-4 \mathrm{a}\left(\delta_{\mathrm{H}} 2.82, \mathrm{~m}\right)$, together with the HMBC correlations between a carboxyl carbon at $\delta_{\mathrm{C}} 169.8$ and $\mathrm{H}-2, \mathrm{H}-4 \mathrm{a}$, and $\mathrm{H}-4 \mathrm{~b}$, corroborated the location of the carboxylic acid moiety at C-1. HMBC connections of $\mathrm{H}-1^{\prime}\left(\delta_{\mathrm{H}} 1.50\right)$ with $\mathrm{C}-2^{\prime}\left(\delta_{\mathrm{C}} 133.7\right), \mathrm{C}-6^{\prime}$ $\left(\delta_{\mathrm{C}} 33.7\right), \mathrm{C}-8^{\prime}\left(\delta_{\mathrm{C}} 28.2\right)$ and $\mathrm{C}-9^{\prime}\left(\delta_{\mathrm{C}} 28.1\right)$, of $\mathrm{H}-8^{\prime}\left(\delta_{\mathrm{H}} 1.00\right)$ and $\mathrm{H}-9^{\prime}\left(\delta_{\mathrm{H}} 0.89\right)$ with $\mathrm{C}-5^{\prime}\left(\delta_{\mathrm{C}} 32.8\right)$, $C-6^{\prime}$, and $C-1^{\prime}\left(\delta_{C} 50.9\right)$, respectively, established the gross sesquiterpenoid structure of 1 . The carbon skeleton is related to abscisic acid [11] and represents a highly reduced derivative through the absence of oxidized functionalities such as a tertiary alcohol at $C-1^{\prime}$ and a carbonyl of a ketone at $C-4^{\prime}$, and the loss of a double bond at C-4 and C-5.

Table 1. NMR spectroscopic data $\left(\mathrm{MeOH}-d_{4}, 700 \mathrm{MHz}\right)$ for roussoellenic acid (1).

\begin{tabular}{cccc}
\hline Position & $\delta_{\mathbf{H}}{ }^{1}$ & $\delta_{\mathrm{C}}{ }^{\mathbf{1}}$ & HMBC $^{2}$ \\
\hline 1 & - & 169.8 & - \\
2 & $5.62, \mathrm{~s}$ & 117.2 & $1,3,4,6$ \\
3 & - & 162.2 & - \\
$4 \mathrm{a}$ & $2.82(\mathrm{ddd}, 11.5,10.5,4.9)$ & 35.1 & $1,2,3,6,1^{\prime}$ \\
$4 \mathrm{~b}$ & $2.48(\mathrm{ddd}, 11.5,10.5,4.9)$ & & \\
$5 \mathrm{a}$ & $1.61^{3}$ & 30.7 & $3,1^{\prime}, 2^{\prime}, 6^{\prime}$ \\
$5 \mathrm{~b}$ & $1.48^{3}$ & & \\
6 & $1.90, \mathrm{~s}$ & 25.5 & $2,3,4,6$ \\
$1^{\prime}$ & $1.50^{3}$ & 50.9 & $4,2^{\prime}, 5^{\prime}, 6^{\prime}, 7^{\prime}, 8^{\prime}, 9^{\prime}$ \\
$2^{\prime}$ & - & 137.7 & - \\
$3^{\prime}$ & $5.31, \mathrm{brs}$ & 121.3 & $1^{\prime}, 2^{\prime}, 4^{\prime}, 7^{\prime}$ \\
$4^{\prime}$ & $1.97^{3}$ & 24.1 & $2^{\prime}, 3^{\prime}, 5^{\prime}$ \\
$5 \mathrm{a}^{\prime}$ & $1.48^{3}$ & 32.8 & $1^{\prime}, 2^{\prime}, 5^{\prime}, 8^{\prime}, 9^{\prime}$ \\
$5 \mathrm{~b}^{\prime}$ & $1.14(\mathrm{dd}, 7.1,6.0)$ & & \\
$6^{\prime}$ & - & 33.7 & - \\
$7^{\prime}$ & $1.72,(\mathrm{~d}, 1.5)$ & 23.8 & $1^{\prime}, 2^{\prime}, 3^{\prime}$ \\
$8^{\prime}$ & $1.00, \mathrm{~s}$ & 28.2 & $1^{\prime}, 5^{\prime}, 6^{\prime}, 9^{\prime}$ \\
$9^{\prime}$ & $0.89, \mathrm{~s}$ & 28.1 & $1^{\prime}, 5^{\prime}, 6^{\prime} 8^{\prime}$ \\
\hline
\end{tabular}

${ }^{1} \delta$ values were established from HSQC-DEPT, COSY and HMBC experiments. ${ }^{2}$ HMBC correlations, optimized for $10 \mathrm{~Hz}$, are from the proton(s) stated to the indicated carbon(s). ${ }^{3}$ Multiplicity not reported due to overlap of signals.

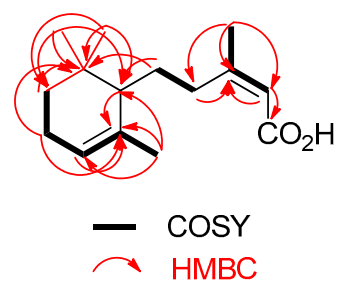

Figure 2. COSY and key HMBC correlations in $\mathbf{1 .}$

The conformation of compound 1 was assigned by analysis of its 2D Nuclear Overhauser Effect SpectroscopY (NOESY) data. A cross-peak between resonances assigned to $\mathrm{H}-5 \mathrm{a} / \mathrm{H}-5 \mathrm{~b}$ and $\mathrm{H}_{3}-8^{\prime}$, and pseudo-axial oriented $\mathrm{H}_{-} \mathrm{1}^{\prime}$ and $\mathrm{H}_{3}-9^{\prime}$ were evident in the spectrum. The $2 \mathrm{Z}$ configuration was assigned based on the cross-peak between $\mathrm{H}-2$ and $\mathrm{H}_{3}-6$. With a substructure akin to the 1,5,5,6-tetrasubstituted cyclohexene of $\alpha$-ionone derivatives and where C-1 ${ }^{\prime}$ is chiral, the absolute configuration of this stereocenter in $\mathbf{1}$ can be easily assigned or correlated. In a study conducted by Soorukram and Knochel [12], the asymmetric synthesis of optically active $\alpha$-ionone (incorporating an alkenone substituent at $C-1^{\prime}$ ) and its aliphatic synthetic precursors was achieved via copper-catalyzed anti-S $S_{N} 2^{\prime}$ reactions of functionalized organozinc substrates. Accordingly, whether the substituent is conjugated (as in $(R)-\alpha$-ionone) or aliphatic (as in $(R)$-dihydro- $\alpha$-ionone), the sign of the specific rotation value remains the same and highly influenced by the chirality present in $C-1^{\prime}$. Thus with a levorotatory value, the absolute configuration of $C-1^{\prime}$ is proposed to be $S$. The structure of $\mathbf{1}$ was first 
reported during a synthetic study of abscisic acid derivatives [13]. However, the characterization data are ambiguous and no NMR and MS spectroscopic data were presented.

Pestabacillin B (2) [14] and cyclo(S-Pro-S-Ile) (3) [15] were identified by comparing their spectroscopic data with values reported in the literature.

Abscisic acid and its derivatives have been detected in culture filtrates of selected saprophytic and plant pathogenic fungi [16]. However, reduced congeners such as $\mathbf{1}$ and $\mathbf{2}$ are rare. Interestingly, compound 2 was produced as a result of a co-culture experiment between the endophytic fungus Pestalotiopsis microspora and Bacillus subtilis [14]. Based on a previously reported biochemical data outlining the biosynthetic pathways en route abscisic acids [17], the cascades entail direct cyclization of farnesyl diphosphate (4) and relay of oxidation reactions. Thus biosynthetically, $\mathbf{1}$ could be derived after the carbocyclization of 4 via stereoselective ring closure of $C-6^{\prime}$ and $C-1^{\prime}$ to afford dihydro- $\alpha$-ionylidenethanol 5, cis-trans isomerization in the conjugated olefin (C-2-C-3), and oxidation of primary alcohol (C-1) to carboxylic acid. Reduction of C-2 olefin in $\mathbf{1}$ followed by P450 monooxygenase [18] driven C-4 allylic oxidation produces compound 2 (Scheme 1 ).

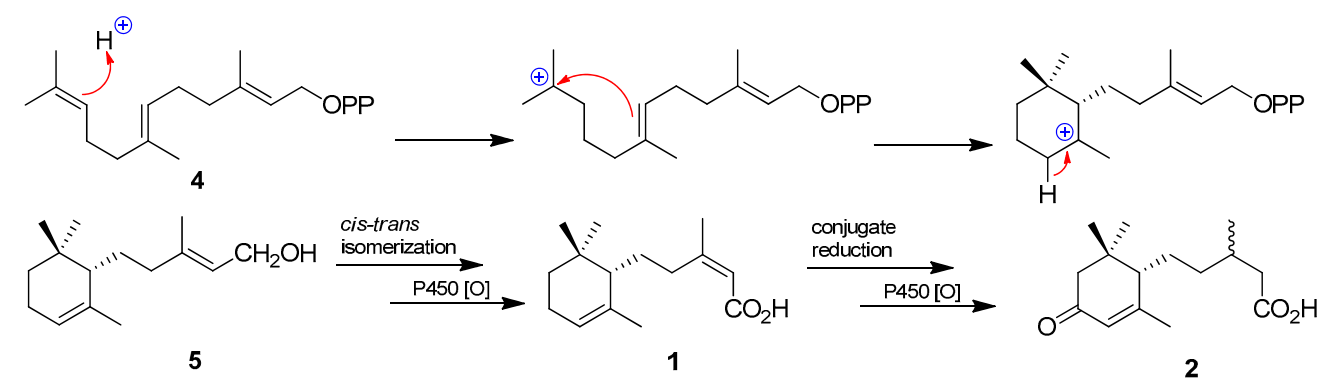

Scheme 1. Putative biogenetic pathway of $\mathbf{1}$ and 2.

The purified compounds were tested for their antimicrobial activities against various organisms (Table 2). Roussoellenic acid (1) showed minimum inhibitory concentrations (MIC) being more significantly inhibitory than pestabacillin B (2). Compound 1 exhibited weak antibacterial activity against Bacillus subtilis, Micrococcus luteus, and Staphylococcus aureus (MIC $=66.7 \mu \mathrm{g} / \mathrm{mL}$ ). It also exhibited antifungal activity with similar MIC values against Mucor hiemalis. The cytotoxicity of compounds $\mathbf{1}$ and $\mathbf{2}$ to KB3.1 and L929 cells were also determined for an initial assessment of cancer cell toxicity. Compound 1 exhibited weak cytotoxic effects on L929 murine fibroblasts and human KB3-1 cancer cells (Table 2).

Table 2. Antimicrobial and cytotoxic activities of compounds $\mathbf{1}$ and $\mathbf{2 .}$

\begin{tabular}{|c|c|c|c|c|}
\hline Strain & Compound 1 & Compound 2 & \multicolumn{2}{|c|}{ Positive Control ( $\mu \mathrm{g} / \mathrm{mL})$} \\
\hline Bacteria & \multicolumn{2}{|c|}{$\mathrm{MIC}(\mu \mathrm{g} / \mathrm{mL})$} & & \\
\hline Bacillus subtilis DSM 10 & 66.7 & - & 4.1 & Oxytetracyclin \\
\hline Chromobacterium violaceum DSM 30191 & - & - & 0.4 & Oxytetracyclin \\
\hline Escherichia coli DSM 1116 & - & - & 3.3 & Oxytetracyclin \\
\hline Micrococcus luteus DSM 1790 & 66.7 & - & 0.2 & Oxytetracyclin \\
\hline Mycobacterium smegmatis ATCC 700084 & - & - & 3.3 & Kanamycin \\
\hline Pseudomonas aeruginosa PA14 & - & - & 1.7 & Gentamycin \\
\hline Staphylococcus aureus DSM 346 & 66.7 & - & 3.3 & Oxytetracyclin \\
\hline \multicolumn{5}{|l|}{ Fungi } \\
\hline Candida albicans DSM 1665 & - & - & 66.7 & Nystatin \\
\hline Mucor hiemalis DSM 2656 & 66.7 & - & 33.3 & Nystatin \\
\hline Pichia anomala DSM 6766 & - & - & 33.3 & Nystatin \\
\hline Rhodoturula glutinis DSM 10134 & - & - & 33.3 & Nystatin \\
\hline Schizosaccharomyces pombe DSM 70572 & - & - & 33.3 & Nystatin \\
\hline Cell lines & \multicolumn{2}{|c|}{ Cytotoxicity $\mathrm{IC}_{50}(\mu \mathrm{g} / \mathrm{mL})$} & & \\
\hline KB 3.1 HeLa & 14 & - & $5 \times 10^{-4}$ & epothilone B \\
\hline L929 & 27 & - & $1.1 \times 10^{-3}$ & epothilone B \\
\hline
\end{tabular}

(-) no activity; Starting concentration for antimicrobial assay and cytotoxicity assay were 66.7 and $300 \mu \mathrm{g} / \mathrm{mL}$, respectively. 
As a rule, all metabolites that are being isolated in our laboratory that showed only moderate to weak antimicrobial and cytotoxic activities, are being subjected to biofilm inhibition assays. The rationale for this procedure is that novel or rare metabolites that have no direct toxic effect on the pathogenic target organisms may still have a potential, e.g., as inhibitors of biofilm formation. As outlined in a recent review [19], and as demonstrated by some of our own recent publications [20,21], several classes of natural products, including fungal metabolites can inhibit the formation of biofilms and thus constitute candidates for combinational therapy as enhancers of the potency of commercial or novel antibiotics.

Thus, roussoellenic acid (1) and pestabacillin B (2) were evaluated against Staph. aureus to determine if they are able to inhibit biofilm formation. Compound 1 inhibited $34 \%$ of the biofilm formed by $S$. aureus at $16 \mu \mathrm{g} / \mathrm{mL}$ test concentration, while compound 2 inhibited $36 \%$ of the bacterial biofilm at $256 \mu \mathrm{g} / \mathrm{mL}$ (Table 3). As compared to the effects reported in our recent publications. compound 1 actually showed stronger activities than the other inhibitors we found so far, including microporenic acids and sclerin derivatives [19,20]. It is also interesting that compound 2 showed weaker effects despite its structural similarity to $\mathbf{1}$. The reasons for this phenomenon remains to be validated in the future. Abscisic acid and some of its derivatives are important hormones in plants. They are involved in the regulation of seed development by controlling desiccation tolerance, storage product deposition, and dormancy [13]. However, to the best of our knowledge, none of the derivatives of abscisic acid has so far been associated with inhibition of biofilm formation in a human pathogen [21]. Our results therefore provide first evidence on how to further pursue this phenomenon.

Table 3. Biofilm inhibitory activity of compounds $\mathbf{1}$ and 2.

\begin{tabular}{cccc}
\hline \multirow{2}{*}{ Test Organisms } & Compound 1 & Compound 2 & Tetracycline \\
\cline { 2 - 4 } & Biofilm Inhibition \% & Biofilm Inhibition \% & Biofilm Inhibition \% \\
\hline \multirow{2}{*}{ Staphylococcus aureus DSM 1104 } & $98 \%(256 \mu \mathrm{g} / \mathrm{mL})$ & $36 \%(256 \mu \mathrm{g} / \mathrm{mL})$ & $88 \%(100 \mu \mathrm{g} / \mathrm{mL})$ \\
& $83 \%(128 \mu \mathrm{g} / \mathrm{mL})$ & $23 \%(128 \mu \mathrm{g} / \mathrm{mL})$ & - \\
& $73 \%(64 \mu \mathrm{g} / \mathrm{mL})$ & - & - \\
\hline
\end{tabular}

(-) no activity.

\section{Materials and Methods}

\subsection{General Information}

Optical rotations were determined using a Perkin-Elmer (Überlingen, Germany) 241 spectrophotometer; ultraviolet (UV) spectra were recorded with a Shimadzu (Duisburg, Germany) UV-2450 UV-Vis spectrophotometer. NMR spectra were recorded on a Bruker (Bremen, Germany) Ascend 700 spectrometer equipped with $5 \mathrm{~mm}$ TXI cryoprobe $\left({ }^{1} \mathrm{H}-700 \mathrm{MHz},{ }^{13} \mathrm{C}-175 \mathrm{MHz}\right)$ spectrometer. HR-ESI-MS mass spectra were recorded using a Bruker (Bremen, Germany) Agilent 1260 series HPLC-UV/Vis system (column $2.1 \times 50$ mm, 1.7 m, C18 Acquity UPLC BEH (waters), solvent $\mathrm{A}: \mathrm{H}_{2} \mathrm{O}+0.1 \%$ formic acid; solvent $\mathrm{B}$ : $\mathrm{AcCN}+0.1 \%$ formic acid, gradient: $5 \% \mathrm{~B}$ for $0.5 \mathrm{~min}$ increasing to $100 \% \mathrm{~B}$ in $19.5 \mathrm{~min}$ and then maintaining $100 \% \mathrm{~B}$ for $5 \mathrm{~min}$, flow rate $0.6 \mathrm{~mL} / \mathrm{min}$, $\mathrm{UV} /$ Vis detection at 200-600 nm combined with ESI-TOF-MS (MaXiS, Bruker, Bremen, Germany) [scan range 100-2500 m/ $z$, capillary voltage $4500 \mathrm{~V}$, dry temperature $200{ }^{\circ} \mathrm{C}$ ]. Chemicals and solvents were obtained from AppliChem GmbH (Darmstadt, Germany), Avantor Performance Materials (Arnhem, Netherlands), Carl Roth GmbH \& Co. KG (Karlsruhe, Germany) and Merck KGaA (Darmstadt, Germany) in analytical and HPLC grade. 


\subsection{Fungal Material}

The specimen Clematis subumbellata Kurz was collected from Chiang Rai, Thailand by one of the authors (C.P.) in May, 2017. The dried herbarium specimen and culture are deposited at Mae Fah Luang culture collections as MFLU 17-1465 and MFLUCC 17-2059, respectively. The fungus was identified as Roussoella sp. by morphological studies and the DNA sequences data ( $5.8 \mathrm{~S}$ gene region, the internal transcribed spacer ITS1 and ITS2 and TEF1-alpha). These sequence data are deposited in GenBank with accession number MH744730 and MH75023, respectively. Genomic DNA Miniprep kit (Bio Basic Canada Inc., Markham, ON, Canada). A Precellys 24 homogenizer (Bertin Technologies, Saint-Quentin-en-Yvelines, France) was used for cell disruption at a speed of $6000 \mathrm{rpm}$ for $40 \mathrm{~s}$ for two times. The ITS gene region were amplified with primers ITS5 and ITS4, while TEF1-alpha were amplified by using 983F and 2218R. According to the interpretations as a new species (see S1), results will be described in a later taxonomic paper.

\subsection{Fermentation and Extraction}

A well-grown mycelial culture of Roussoella sp. (15 days old) on yeast-malt glucose (YMG) agar plates ( $1 \%$ malt extract, $0.4 \%$ D-Glucose, $0.4 \%$ Yeast extract, $2 \%$ agar, $\mathrm{pH} 6.3$ ) was cut into small pieces using a $7 \mathrm{~mm}$ cork borer. Five plugs were transferred into each of the 30 sterilized Erlenmeyer flasks containing liquid YMG media. The cultures were incubated in a dark room at 25 ${ }^{\circ} \mathrm{C}$ on a rotary shaker $(140 \mathrm{rpm})$ for seven days. After the sugar was consumed, fermentation was terminated 3 days after glucose depletion. The mycelia and supernatant were separated using vacuum filtration, and the mycelia were homogenized and extracted with acetone under ultrasonic conditions $(3 \times)$. The combined acetone extracts were evaporated in vacuo $\left(40^{\circ} \mathrm{C}\right)$, and the crude product was suspended in distilled water and extracted with an equal volume of ethyl acetate $(4 \times)$. The aqueous layer was discarded and the organic phase dried over anhydrous sodium sulfate. The resulting ethyl acetate extracts were evaporated to dryness to afford $1 \mathrm{~g}$ of crude material. The supernatant was mixed with Amberlite XAD-16 N (30 g per $1 \mathrm{~L}$ ) and extracted according to a previously described procedure [19].

\subsection{Isolation of $\mathbf{1}-\mathbf{3}$}

The crude extracts from the mycelia and supernatant yielded a yellowish to brown solid residue. The extracts in methanol were filtered on a RP solid-phase cartridge (Strata-X $33 \mathrm{~mm}$, polymeric reversed phase; Phenomenex Aschaffenburg, Germany) to yield $800 \mathrm{mg}$ of crude material. Purification was achieved on a preparative HPLC (Gilson, Middleton, WI, USA) equipped with a GX-271 Liquid Handler, a 172 DAD, and a 305 and 306 pump (with 50SC Piston Pump Head) [22]. A VP Nucleodur 100-10 C18 ec column $(150 \times 40 \mathrm{~mm}, 7 \mu \mathrm{m}$; Macherey-Nagel) was used as stationary phase. The mobile phase was composed of deionized water (Milli-Q, Millipore, Schwalbach, Germany) with $0.05 \%$ trifluoroacetic acid (solvent $\mathrm{A}$ ) and acetonitrile (AcCN, HPLC-grade) with $0.05 \%$ trifluoroacetic acid (solvent B). Separation was carried out according to the following gradients: linear gradient of solvent B from $10 \%$ to $100 \%$ in $35 \mathrm{~min}$, followed by isocratic conditions at $100 \%$ for $10 \mathrm{~min}$, with a flow rate of $35 \mathrm{~mL} / \mathrm{min}$. UV detection was carried out at 210, 280 and $354 \mathrm{~nm}$. Fractions were collected and combined according to the observed peaks. Compound $\mathbf{1}(8.2 \mathrm{mg})$ was obtained at a retention time $\left(t_{R}\right)$ of $36.5-37 \mathrm{~min}$ while compounds $2(12 \mathrm{mg})$ and $3(6.2 \mathrm{mg})$ were yielded at $t_{R}=37-38 \mathrm{~min}$ and $t_{R}=16.5-17.5 \mathrm{~min}$, respectively. The fractions eluting at $t_{R}=36.5-37 \mathrm{~min}$ were bioactive and contained 1 with some impurity. This fraction was rechromatographed on a Gemini 10u C18 110A column $(250 \times 21.20 \mathrm{~mm}, 10 \mu \mathrm{m})$ using the following gradients; linear gradient of solvent B from $40 \%$ to $100 \%$ in $20 \mathrm{~min}$, followed by isocratic conditions at $100 \%$ for $20 \mathrm{~min}$, with a flow rate of $15 \mathrm{~mL} / \mathrm{min}$. Compound 1 was obtained at $\mathrm{t}_{R}=26-27 \mathrm{~min}$ to give a final yield of $2.7 \mathrm{mg}$.

Roussoellenic acid (1): colorless oil; $[\alpha]]_{\mathrm{D}}^{25}=-106.0$ (c $\left.0.1, \mathrm{MeOH}\right) ;{ }^{1} \mathrm{H}-\mathrm{NMR}$ and ${ }^{13} \mathrm{C}-\mathrm{NMR}$ data, see Table 1; HR-ESIMS $[\mathrm{M}+\mathrm{H}]^{+} m / z 237.1853$ (calc. 237.1849, $\mathrm{C}_{15} \mathrm{H}_{25} \mathrm{O}_{2}$ ); see Figure S8. 


\subsection{Biological Activities}

Antimicrobial Activity and Cytotoxicity Assays

The MIC of the test compounds against bacteria, yeasts, and filamentous fungi were determined using a serial dilution technique on 96-well microtiter plates [23]. In vitro cytotoxicity $\left(\mathrm{IC}_{50}\right)$ of compounds 1 and 2 were determined against mouse fibroblast L929 and HeLa (KB-3.1) cell lines according to a previously described procedure [24]. The assays for determination of antimicrobial and cytotoxic activities were performed according to our standard protocols, two times with each assay carried out in duplicate regarding the concentration range of samples.

\subsection{Inhibition of Biofilm Formation}

The biofilm forming strain Staphylococcus aureus DSM1104 was enriched overnight on a casein-peptone soymeal-peptone (CASO) medium from Sigma-Aldrich (MO, United States of America) containing $4 \%$ glucose ( $\mathrm{pH} 7.0$ ). The ability of $\mathbf{1}$ and $\mathbf{2}$ to prevent Staph. aureus biofilm formation was performed using a previously described protocol [20].

The assay was carried out in 96-well tissue microtiter plates (TPP, Switzerland). The turbidity of the pre-inoculum was adjusted to obtain a $0.5 \mathrm{McFarland}$ standard and the test compounds were serially diluted ( 1 to $256 \mu \mathrm{g} / \mathrm{mL}$ ) and incubated for $20 \mathrm{~h}$ at $37^{\circ} \mathrm{C}$. Methanol and CASO medium containing $4 \%$ glucose were used as a negative controls and tetracycline $(100 \mu \mathrm{g} / \mathrm{mL})$ was used as the positive control. The biofilm inhibition assay was performed in triplicate. After incubation, biofilm formations were measured after staining with $0.1 \%$ crystal violet solution (Fluka, Steinheim, Germany).

Supplementary Materials: The following are available online: Figures S1.1-1.2, S2-S15, and Table S13.

Author Contributions: C.P. contributed to fungal specimen collection, isolation, species identification, fermentation, isolation of the compounds, determination of biological activities, and manuscript writing; A.P.G.M. contributed to the isolation of compounds, structure elucidation, guiding the experiments, analyses of the spectral data, and manuscript writing; K.T.Y. contributed to determination of biological activities; K.D.H. contributed materials, facilities, and experiment guidance; M.S. contributed to the project organization, experimental guidance, and manuscript writing.

Funding: This work was supported by Royal Golden Jubilee PhD Program (RGJ) under Thailand Research Fund and the German Academic Exchange Service (DAAD) for a joint TRF-DAAD [PPP 2017-2018] academic exchange grant to K.D. Hyde and M. Stadler and the RGJ for a personal grant to C. Phukhamsakda (Scholarship number [PHD/0020/2557]) and by the Alexander von Humboldt Foundation (Georg-Forster Research Fellowship to A.P.G.M.).

Acknowledgments: We thank Martin van de Bult for sample collection guidance. We also thank Wera Collisi and Christel Kakoschke for conducting the cytotoxicity assay and NMR spectroscopic measurements, respectively.

Conflicts of Interest: The authors declare no conflict of interest.

\section{References}

1. Beimforde, C.; Feldberg, K.; Nylinder, S.; Rikkinen, J.; Tuovila, H.; Dörfelt, H.; Gube, M.; Jackson, D.J.; Reitner, J.; Seyfullah, L.J.; et al. Estimating the phanerozoic history of the Ascomycota lineages: Combining fossil and molecular data. Mol. Phylogenet. Evol. 2014, 78, 386-398. [CrossRef] [PubMed]

2. Kirk, P.M.; Cannon, P.F.; Minter, D.W.; Stalpers, J.A. Dictionary of the Fungi, 10th ed.; CABI: Wallingford, UK, 2008; pp. 55-56.

3. Wijayawardene, N.N.; Hyde, K.D.; Lumbsch, H.T.; Liu, J.K.; Maharachchikumbura, S.S.; Ekanayaka, A.H.; Tian, Q.; Phookamsak, R. Outline of Ascomycota: 2017. Fungal Divers. 2018, 88, 167-263. [CrossRef]

4. Chagas, F.; Caraballo-Rodriguez, A.; Pupo, M. Endophytic fungi as a source of novel metabolites. In Biosynthesis and Molecular Genetics of Fungal Secondary Metabolites; Zeilinger, S., Martín, J.F., García-Estrada, C., Eds.; Fungal Biology; Springer: New York, NY, USA, 2015; Volume 2, pp. 123-176.

5. Gutierrez, R.M.P.; Gonzalez, A.M.N.; Ramirez, A.M. Compounds derived from endophytes: A review of phytochemistry and pharmacology. Curr. Med. Chem. 2012, 19, 2992-3030. [CrossRef] [PubMed]

6. Gonzalez, M.J.M.; Chooi, Y.H.; Breen, S.; Solomon, P.S. The past, present and future of secondary metabolite research in the Dothideomycetes. Mol. Plant Pathol. 2015, 16, 92-107. [CrossRef] [PubMed] 
7. Liu, J.K.; Phookamsak, R.; Dai, D.Q.; Tanaka, K.; Jones, E.G.; Xu, J.C.; Chukeatirote, E.; Hyde, K.D. Roussoellaceae, a new pleosporalean family to accommodate the genera Neoroussoella gen. nov., Roussoella and Roussoellopsis. Phytotaxa 2014, 181, 1-33. [CrossRef]

8. Takekawa, H.; Tanaka, K.; Fukushi, E.; Matsuo, K.; Nehira, T.; Hashimoto, M. Roussoellols A and B, tetracyclic fusicoccanes from Roussoella hysterioides. J. Nat. Prod. 2013, 76, 1047-1051. [CrossRef] [PubMed]

9. Honmura, Y.; Takekawa, H.; Tanaka, K.; Maeda, H.; Nehira, T.; Hehre, W.; Hashimoto, M. Computation-assisted structural elucidation of epoxyroussoeone and epoxyroussoedione isolated from Roussoella japanensis KT1651. J. Nat. Prod. 2015, 78, 1505-1510. [CrossRef] [PubMed]

10. Ferreira, E.L.F.; Williams, D.E.; Ióca, L.P.; Morais-Urano, R.P.; Santos, M.F.C.; Patrick, B.O.; Elias, L.M.; Lira, S.P.; Ferreira, A.G.; Passarini, M.R.Z.; et al. Structure and biogenesis of roussoellatide, a dichlorinated polyketide from the marine-derived fungus Roussoella sp. DLM33. Org. Lett. 2015, 17, 5152-5155. [CrossRef] [PubMed]

11. Millborrow, B.V. The origin of the methyl groups of abscisic acid. Phytochemistry 1975, 14, $2403-2405$. [CrossRef]

12. Soorukram, D.; Knochel, P. Enantioselective synthesis of $\alpha$-ionone derivatives using an anti $\mathrm{S}_{\mathrm{N}} 2$ substitution of functionalized zinc organometallics. Org. Lett. 2004, 6, 2409-2411. [CrossRef] [PubMed]

13. Oritani, T.; Yamashita, K. Studies on abscisic acid. Agric. Biol. Chem. 1970, 34, 830-837. [CrossRef]

14. Liu, S.; Dai, H.; Heering, C.; Jania, C.; Lin, W.; Liu, Z.; Proksch, P. Inducing new secondary metabolites through co-cultivation of the fungus Pestalotiopsis sp. with the bacterium Bacillus subtilis. Tetrahedron Lett. 2017, 58, 257-261. [CrossRef]

15. Pedras, M.; Soledade, C.; Yu, Y.; Liu, J.; Tandron-Moya, Y.A. Metabolites produced by the phytopathogenic fungus Rhizoctonia solani: Isolation, chemical structure determination, syntheses and bioactivity. Z. Naturforsch. C J. Biosci. 2005, 60, 717-722. [CrossRef]

16. Kettner, J.; Dörffling, K. Biosynthesis and metabolism of abscisic acid in tomato leaves infected with Botrytis cinerea. Planta 1995, 196, 627-634. [CrossRef]

17. Krochko, J.E.; Abrams, G.D.; Loewen, M.K.; Abrams, S.R.; Cutler, A.J. (+)-Abscisic acid 8'-hydroxylase is a cytochrome P450 monooxygenase. Plant Physiol. 1998, 118, 849-860. [CrossRef] [PubMed]

18. Siewers, V.; Smedsgaard, J.; Tudzynski, P. The P450 monooxygenase BcABA1 is essential for abscisic acid biosynthesis in Botrytis cinerea. Appl. Environ. Microbiol. 2004, 70, 868-876. [CrossRef] [PubMed]

19. Chepkirui, C.; Yuyama, K.; Wanga, L.; Decock, C.; Matasyoh, J.; Abraham, W.R.; Stadler, M. Microporenic acids A-G, biofilm inhibitors and antimicrobial agents from the basidiomycete Microporus sp. J. Nat. Prod. 2018, 81, 778-784. [CrossRef] [PubMed]

20. Yuyama, K.; Chepkirui, C.; Wendt, L.; Fortkamp, D.; Stadler, M.; Abraham, W.R. Bioactive compounds produced by Hypoxylon fragiforme against Staphylococcus aureus biofilms. Microorganisms 2017, 5, 80. [CrossRef] [PubMed]

21. Buommino, E.; Scognamiglio, M.; Donnarumma, G.; Fiorentino, A.; D'Abrosca, B. Recent advances in natural product-based anti-biofilm approaches to control infections. Mini Rev. Med. Chem. 2014, 14, 1169-1182. [CrossRef] [PubMed]

22. Narmani, A.; Pichai, S.; Palani, P.; Arzanlou, M.; Surup, F.; Stadler, M. Daldinia sacchari (Hypoxylaceae) from India produces the new cytochalasins Saccalasins A and B and belongs to the D. eschscholtzii species complex. Mycol. Prog. 2018, 1-11. [CrossRef]

23. Surup, F.; Kuhnert, E.; Böhm, A.; Pendzialek, T.; Solga, D.; Wiebach, V.; Engler, H.; Berkessel, A.; Stadler, M.; Kalesse, M. The rickiols, 20-, 22-, and 24-membered macrolides from the ascomycete Hypoxylon rickii. Chem. Eur. J. 2018, 24, 2200-2213. [CrossRef] [PubMed]

24. Sandargo, B.; Thongbai, B.; Stadler, M.; Surup, F. Cysteine-derived pleurotin congeners from the nematode-trapping basidiomycete Hohenbuehelia grisea. J. Nat. Prod. 2018, 81, 286-291. [CrossRef] [PubMed]

Sample Availability: Samples of the compounds 1-3 are available from the authors. 